\title{
DOSSIÊ: SENTIDOS DO FAZER JUDICIAL E POLICIAL: ADMINISTRAÇÃO DE CONFLITOS E SISTEMA DE JUSTIÇA
}

\section{FERNANDA BESTETTI DE VASCONCELLOS}

Professora Adjunta do Departamento de Sociologia e do Programa de Pós-Graduação em Segurança Cidadã (UFRGS). Pesquisadora do Instituto Nacional de Estudos Comparados em Administração Institucional de Conflitos (INCT-InEAC) e do Grupo de Pesquisas em Políticas Públicas de Segurança e Administração da Justiça Criminal (GPESC/PUCRS) e associada ao FBSP. Contato: fernanda.bestetti@ufrgs.br

\section{IZABEL SAENGER NUÑEZ}

Doutora em Antropologia pelo PPGA/UFF (2018). Mestre em Ciências Jurídicas e Sociais pelo PPGSD/UFF (2012). Bacharel em Ciências Jurídicas e Sociais pela PUCRS (2007). Atualmente é pesquisadora de pós doutorado (PNPD/CAPES) vinculada ao Núcleo Fluminense de Estudos e Pesquisa (NUFEP/PPGA/UFF). É vice coordenadora do Núcleo de Estudos e Pesquisas sobre Sujeitos, Sociedade e Estado (NEPSSE/UFF) e pesquisadora do Instituto Nacional de Estudos Comparados em Administração Institucional de Conflitos (INCT-InEAC) e da FGV Direito Rio. Contato: izabelsn@gmail.com.

Os trabalhos incluídos nesse dossiê foram apresentados, em versões preliminares, no Grupo de Trabalho intitulado Sentidos do fazer judicial e policial: administração de conflitos e Sistema de Justiça, que teve a sua primeira edição no $8^{\circ}$ Encontro de Pesquisa Empírica em Direito, realizado no ano de 2018, na Universidade Federal de Juiz de Fora/UFJF. O Grupo de Trabalho é fruto de uma parceria entre pesquisadoras do Instituto Nacional de Estudos Comparados em Administração de Conflitos, o INEAC', sediado na UFF, mas que conta com pesquisadoras e pesquisadores de diferentes estados do país e de fora dele. Os interesses comuns e experiências de pesquisa direcionaram os objetivos da criação do GT: a ideia de conhecer e debater com outros (as) pesquisadores (as) seus processos de produção de pesquisas sobre os fazeres judicial e policial.

A iniciativa de criação do grupo de trabalho está vinculada a uma tradição das ciências sociais brasileiras que, desde a década de 80, têm voltado o olhar para a administração de conflitos produzida pelo sistema de justiça. O crescimento dessas pesquisas no contexto nacional teve como reflexo, por exemplo, a criação do GT Direito e Sociedade nos encontros anuais da ANPOCS, que aconteceram entre os anos de 1979 até 1989. Desde então, tanto o campo da antropologia quanto o da sociologia, e também o da ciência política, vêm produzindo pesquisas sobre as representações e práticas dos agentes desse sistema, constituindo o que se pode chamar de um campo de estudos sociojurídicos. Tais trabalhos têm utilizado diferentes abordagens teóricas e metodológicas para compreender fenômenos jurídicos e apreender os diversos sentidos de fazer justiça e do fazer judicial e policial, produzindo assim uma agenda de pesquisa e criando um espaço de confluência e diálogo entre o Direito e as Ciências Sociais.

A ideia de modificar a perspectiva de análise do Direito, observando o mesmo como um fenômeno social, em contraste com o que tradicionalmente fazem os profissionais que atuam dentro do que pode ser

1 Trata-se de um empreendimento coletivo, aprovado em fevereiro de 2009, pelo Ministério de Ciência e Tecnologia, através do Programa "Institutos de Ciência e Tecnologia" - Edital 15/08, proposto pelo CNPq em pareceria com a FAPERJ. Faz, então, parte de um conjunto de 122 INCTs aprovados à época, dentre dos quais somente dois foram constituídos na área induzida de Segurança Pública, um com sede no estado do Rio de Janeiro (UFF) e um no estado de São Paulo (USP). 
chamado campo jurídico (Bourdieu, 1989), fornece novos elementos para a sua compreensão e permite a produção reflexões originais sobre o seu funcionamento. É preciso considerar que, no Brasil, o campo jurídico não é majoritariamente afeito a relativizar categorias e conceitos e/ou desconstruir verdades consagradas: o olhar dogmático do "dever ser" costuma apresentar-se como imperativo neste campo (Kant de Lima e Lupetti Baptista, 2014). Neste sentido, voltar o olhar do pesquisador para o "ser" (que é precisamente o que o olhar empírico se propõe) proporciona a observação do Direito enquanto fenômeno concreto e permite que sua análise seja realizada a partir de um olhar externo (Sadek, 2002).

No mesmo sentido, a sociedade brasileira parece permanecer refém de uma cultura jurídica que, imiscuída nas relações sociais cotidianas, busca a administração de conflitos, ora pela ideologia da harmonia, ora pela da repressão. Tanto uma quanto a outra aparentam resultar de uma percepção hierarquizada e desigual da sociedade, de modo que manifestações populares ou do cidadão comum, devem ser sufocadas, quando parecem ameaçar o status quo vigente. Isto significa que o motor das relações sociais e das políticas da ordem social seguem o princípio jurídico de que "manda quem pode, obedece quem tem juízo" ou do ritual do "você sabe com quem está falando?" (Mello e Azevedo, 2017).

Assim, desde uma perspectiva crítica, que observa a atuação do Estado na administração de conflitos por meio do sistema de justiça formal como um fenômeno passível de análises amparadas por metodologias de pesquisa utilizadas pelas ciências sociais, verificam-se como necessárias para a compreensão do fenômeno questões como: a quem tais práticas atendem? Quais são os valores morais e as moralidades que as informam? Quais os seus significados nos diferentes contextos em que ocorrem? O que se entende por "pacificação social"? Trata-se, por fim, de um mecanismo de autonomização, comunicação, satisfação e conquista da justiça pelos indivíduos, ou de normalização do seu comportamento?

O peso da tradição inquisitorial (Kant de Lima e Mouzinho, 2017), a baixa adesão ao paradigma dos direitos humanos, a interveniência de moralidades que enfatizam hierarquias sociais e desigualdades (Nuñez, 2018), especialmente de classe e de gênero, a validação da violência como forma legítima de resolver conflitos, são características recorrentemente apontadas por pesquisas desenvolvidas especificamente sobre a justiça criminal: a baixa resolutividade dos crimes de homicídio (Cerqueira, 2012; Ribeiro, 2014; Costa, 2015; ), o crescimento de índices de violência letal policial e a quase inexistência de práticas que busquem coibir de forma efetiva tal padrão de atuação institucional (FBSP, 2019; 2018; 2017; 2016; 2015) e a violência contra a mulher encontra sérias barreiras para ser adequadamente administrada pelas vias judiciais. (Gregori, 2006; Debert e Gregori, 2008; Debert e Oliveira, 2014; Vasconcellos, 2019).

Ainda, os estudos tendem a enfatizar a emergência de novos conflitos institucionais, de saberes e de práticas no campo da administração institucional de conflitos e buscam encontrar fissuras nas concepções e moralidades dos agentes judiciais. A maioria destes estudos demonstra a existência de enormes barreiras organizacionais e valorativas para o sucesso de inovações especialmente na justiça criminal (Costa, 2015; Azevedo, 2001), assim como nos Juizados Especiais (Lima, 2014; Azevedo, 2000) e também na esfera cível (Baptista, 2013). O papel crescente do Ministério Público (Arantes, 1999; Kerche, 2018) na definição das tendências judiciárias e o papel de instituições alternativas ao penal, seja a justiça restaurativa, seja a rede de atendimento e proteção às mulheres em situação de violência (Vasconcellos, 2019), foram alguns dos novos temas de pesquisa que emergiram na última década.

Nesse dossiê estão reunidos trabalhos que se voltaram para o funcionamento do sistema de justiça e policial, no contexto brasileiro. O texto escrito por Otávio Fantoni Constantino, intitulado A política de 
atendimento aos presos provisórios da Defensoria Pública de São Paulo atenta para a atuação dessa instituição, ainda muito pouco estudada no contexto nacional. Para tanto, traz reflexões sobre a efetivação de novos procedimentos no contexto do referido órgão estatal. Ao analisar como se deu a implementação de uma política pública, nos mostra as complexidades e os desafios inerentes ao processo de transformação das leis em práticas, desde a criação de sucessivas regulamentações até a dicotomia explicitada entre as comarcas do "interior" e da "capital" que revelam as hierarquizações no texto da lei.

O artigo de Lívia Bastos Lages, intitulado O sistema acusatório diante da prisão em flagrante: como o direito a defesa é exercido em fase de audiência de custódia?, nos apresenta reflexões sobre as audiências de custódia. Mais especialmente, sobre como o direito de defesa tem sido tratado, respeitado ou não, no contexto de realização dessas audiências. Por meio da apresentação de dados quanti e qualitativos, a autora demonstra a existência de uma distância entre os princípios orientadores do processo penal e a prática cotidiana dos operadores do direito, na esteira do que diversas pesquisas já vêm demonstrando sobre o funcionamento do sistema de justiça criminal brasileiro.

O trabalho de Perla Alves Bento de Oliveira Costa, "Tem que abordar para conhecer" - o nascimento do X-9 : um instrumento de investigação utilizado pelos policiais militares do Estado do Rio de Janeiro, descreve ao leitor as abordagens policiais no caso de usuários de drogas e como esses usuários posteriormente se transformam em informantes da polícia, formando um "circuito moral de trocas". A pesquisa indica ainda como o processo de incriminação se dá na prática, bem como os usos da informação como "mercadoria política" (Misse, 1997, 2006) que forma um sistema de trocas. A inovação reside também no diálogo da pesquisadora com policiais militares e nos dados qualitativos que é capaz de produzir, justamente em razão da sua atuação profissional, ela própria policial militar.

Finalmente, o artigo Uma luz no "fundo do poço": uma análise das premissas do tratamento oferecido aos policiais militares "dependentes químicos" pela Polícia Militar do Estado do Rio de Janeiro, de Fernanda Novaes Cruz, nos apresenta um interessante olhar sobre o tratamento de policiais militares dependentes químicos, no contexto interno da corporação. Ao acompanhar a equipe que atende esses profissionais, a pesquisadora dialoga com os conceitos de instituição total e instituição reinventiva, propondo um conceito híbrido ao elaborar um modelo de análise capaz de dar conta dos desafios e das complexidades dessa abordagem. Ao mesmo tempo, mostra as moralidades que levam à busca por tratamento por parte dos policiais, que não se explicitam pelo uso de substancias químicas ilícitas, mas sim no receio de expulsão por da corporação baseado em outras justificativas como atrasos e condutas classificadas como "inapropriadas".

Esperamos, então, que os textos aqui reunidos sejam integrados ao acervo de pesquisas sobre segurança pública e justiça criminal, que vem sendo formado desde a década de 1980 em nosso país, permitindo com isso o alargamento da compreensão de fenômenos sociais tão complexos e expandido a produção intelectual nacional. Com isso nossos gestores poderão, quem sabe, elaborar melhores e mais eficazes políticas públicas baseadas em evidências científicas. 


\section{REFERÊNCIAS}

ARANTES, Rogério Bastos. Direito e política: o Ministério Público e a defesa dos direitos coletivos. Rev. bras. Ci. Soc., São Paulo, v. 14, n. 39, p. 83-102, fev. 1999.

AZEVEDO, Rodrigo G. de. Juizados especiais criminais: uma abordagem sociológica sobre a informalização da justiça penal no Brasil. Rev. bras. Ci. Soc., São Paulo, v. 16, n. 47, out. 2001.

. Informalização da Justiça e Controle Social - Estudo Sociológico da Implementação dos Juizados Especiais Criminais em Porto Alegre. São Paulo: IBCCRIM, 2000.

BAPTISTA, Bárbara Gomes Lupetti. Paradoxos e ambiguidades da imparcialidade judicial: entre" quereres" e" poderes". Sergio Antonio Fabris Editor, 2013.

BOURDIEU, Pierre. O Poder Simbólico. Lisboa: Difusão Editorial, 1989.

CERQUEIRA, Daniel. Mortes violentas não esclarecidas e impunidade no Rio de Janeiro. Econ. Apl., Ribeirão Preto, v. 16, n. 2, p. 201-235, jun. 2012

COSTA, Arthur Trindade M.. (2015), "A (in)efetividade da justiça criminal brasileira. Uma análise do fluxo de justiça dos homicídios no Distrito Federal". Civitas, Porto Alegre, 15, 1: 7-10.

DEBERT, Guita Grin; GREGORI, Maria Filomena. Violência e gênero: novas propostas, velhos dilemas. Rev. bras. Ci. Soc., São Paulo, v. 23, n. 66, fev. 2008.

DEBERT, Guita Grin; OLIVEIRA, Marcella Beraldo de. Os modelos conciliatórios de solução de conflitos e a "violência doméstica". Cad. Pagu, Campinas, n. 29, dez. 2007.

FÓRUM BRASILEIRO DE SEGURANÇA PÚBLICA. Anuário Brasileiro de Segurança Pública 2019. São Paulo, 2019.

Anuário Brasileiro de Segurança Pública 2018. São Paulo, 2018.

Anuário Brasileiro de Segurança Pública 2017. São Paulo, 2017.

Anuário Brasileiro de Segurança Pública 2016. São Paulo, 2016.

Anuário Brasileiro de Segurança Pública 2015. São Paulo, 2015.

GREGORI, Maria Filomena. Delegacias de Defesa da Mulher de São Paulo e as instituições: paradoxos e paralelismos. In: Debert, Guita G.; Gregori, Maria Filomena e Piscitelli, Adriana (orgs). Gênero e Distribuição da Justiça: as delegacias de defesa da mulher na construção das diferenças. Coleção Encontros. Campinas: Pagu/UNICAMP, 2006.

KANT DE LIMA, Roberto e LUPETTI BAPTISTA, Bárbara Gomes. Como a Antropologia pode contribuir para a pesquisa jurídica? Um desafio metodológico. Anuário Antropológico. I | 2014, 9-37. Disponível em: <http://journals.openedition.org/aa/618; DOI : 10.4000/aa.618>. Acesso em: 14, fev., 2018.

KANT DE LIMA, Roberto; MOUZINHO, Glaucia Maria Pontes. (2016), Produção e reprodução da tradição inquisitorial no Brasil: Entre delações e confissões premiadas. Dilemas - Revista de Estudos de Conflito e Controle Social, 9 (3), 505-529.

KERCHE, Fábio. Independência, Poder Judiciário e Ministério Público. Cad. CRH, Salvador, v. 31, n. 84, p. 567-580, dez. 2018. 
LIMA, Michel Lobo Toledo. Próximo da Justiça e Distante do Direito: Um Estudo Num Juizado Especial Criminal do Rio de Janeiro. Rio de Janeiro. 2014. 170 p. Tese de Doutorado. Dissertação (Mestrado em Sociologia). Programa de Pós-Graduação em Sociologia (IESP) da UERJ. 2014.

MELLO, Kátia Sento-Sé e AZEVEDO, Rodrigo Ghiringhelli de. Mecanismos alternativos de resolução de conflitos na justiça brasileira: um balanço. In VALOIS et. al (orgs.), Justiça Restaurativa. Belo Horizonte: Ed. D’Plácido, 2017.

MISSE, Michel. As ligações perigosas: mercado informal ilegal, narcotráfico e violência no Rio.. Contemporaneidade e Educação, Rio de Janeiro, v. 1, p. 93-116, 1997.

Crime e Violência no Brasil Contemporâneo: Estudos de Sociologia do Crime e da

Violência Urbana. 1. ed. Rio de Janeiro: Lumen Juris, 2006.

NUÑEZ, Izabel Saenger. "Aqui não é casa de vingança, é casa de justiça!": moralidades, hierarquizações e desigualdades na administração de conflitos no Tribunal do Júri. 2018. 273 f., Tese (Doutorado em Antropologia). Programa de Pós-Graduação em Antropologia da Universidade Federal Fluminense. Niterói: 2018.

OLIVEIRA, Fabiana Luci de (org). Justiça em Foco: estudos empíricos. Rio de Janeiro: Editora FGV, 2012. RIBEIRO, Ludmila Mendonça. Mensurando o tempo do processo de homicídio doloso em cinco capitais. 1. ed. Brasília: Ministério da Justiça, Secretaria de Reforma do Judiciário, 2014.

SADEK, Maria Tereza. Estudos sobre o sistema de justiça. In: O que ler na ciência social brasileira (19702002). São Paulo: Associação Nacional de Pesquisa e Pós-graduação em Ciências Sociais. 2002.

VASCONCELLOS, Fernanda B.. Punir, proteger, prevenir? : a lei Maria da Penha e as limitações da administração dos conflitos conjugais violentos através da utilização do direito penal. 1. ed. Rio de Janeiro - RJ: Autografia, 2019. 
Dossiê: Sentidos do fazer judicial e policial: administração de conflitos e Sistema de Justiça Fernanda Bestetti de Vasconcellos e Izabel Saenger Nuñez
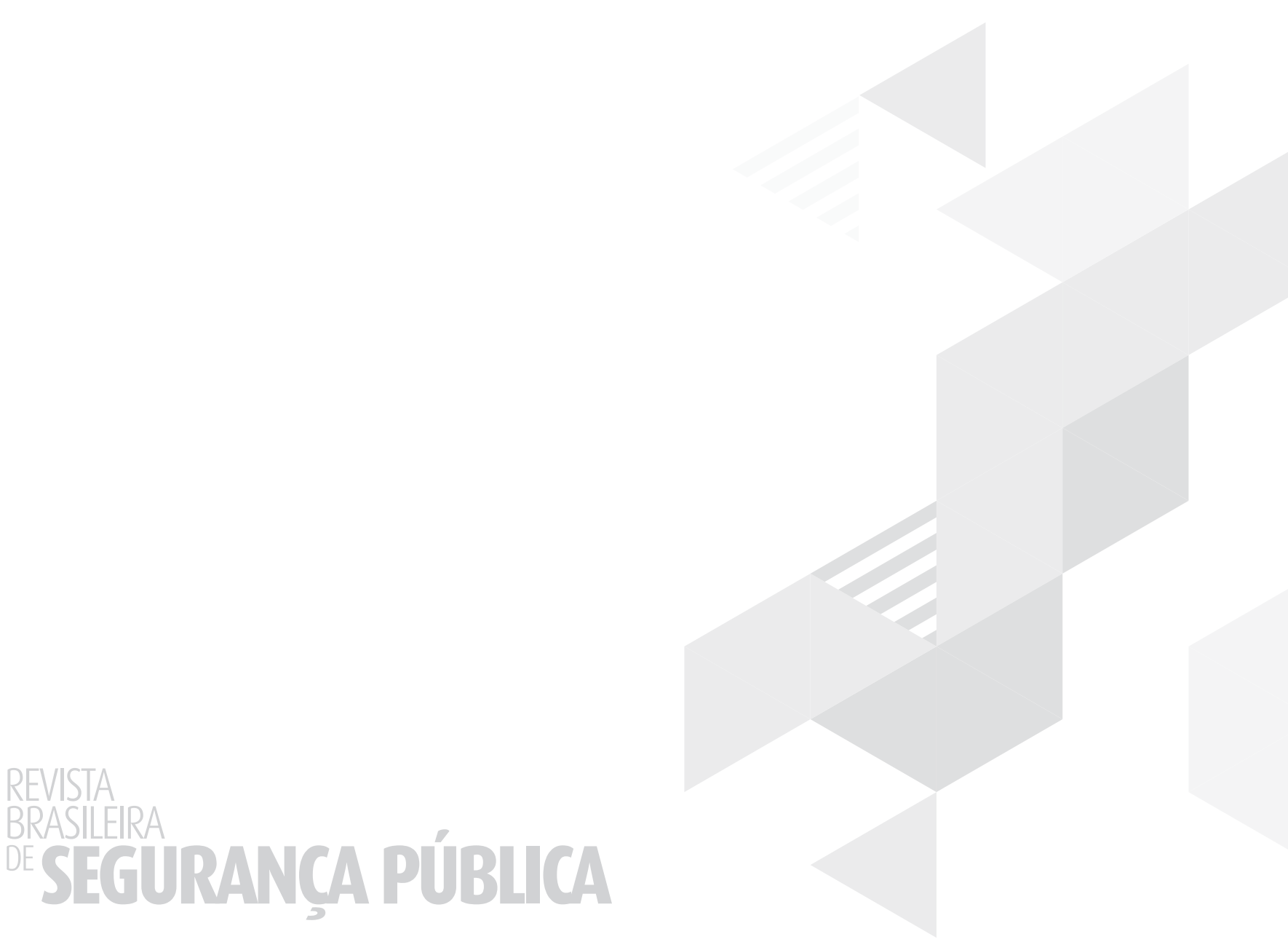